\title{
Towards standardisation of cell-free DNA measurement in plasma: controls for extraction efficiency, fragment size bias and quantification
}

\author{
Alison S. Devonshire • Alexandra S. Whale • \\ Alice Gutteridge • Gerwyn Jones • Simon Cowen • \\ Carole A. Foy • Jim F. Huggett
}

Received: 28 January 2014 / Revised: 26 March 2014 / Accepted: 14 April 2014 / Published online: 24 May 2014

(C) The Author(s) 2014. This article is published with open access at Springerlink.com

\begin{abstract}
Circulating cell-free DNA (cfDNA) is becoming an important clinical analyte for prenatal testing, cancer diagnosis and cancer monitoring. The extraction stage is critical in ensuring clinical sensitivity of analytical methods measuring minority nucleic acid fractions, such as foetal-derived sequences in predominantly maternal cfDNA. Consequently, quality controls are required for measurement of extraction efficiency, fragment size bias and yield for validation of cfDNA methods. We evaluated the utility of an external DNA spike for monitoring these parameters in a study comparing three specific cfDNA extraction methods [QIAamp ${ }^{\circledR}$ circulating nucleic acid (CNA) kit, NucleoSpin ${ }^{\circledR}$ Plasma XS (NS) kit and FitAmp ${ }^{\mathrm{TM}}$ plasma/serum DNA isolation (FA) kit] with the commonly used QIAamp DNA blood mini (DBM) kit. We found that the extraction efficiencies of the kits ranked in the order CNA kit $>$ DBM kit $>$ NS kit $>$ FA kit, and the CNA and NS kits gave a better representation of smaller DNA fragments in the extract than the DBM kit. We investigated means of improved reporting of cfDNA yield by comparing quantitative PCR measurements of seven different reference gene assays in plasma samples and validating these with digital PCR. We noted that the cfDNA quantities based on
\end{abstract}

Published in the topical collection Nucleic Acid Quantification with guest editors Hendrik Emons and Philippe Corbisier.

Electronic supplementary material The online version of this article (doi:10.1007/s00216-014-7835-3) contains supplementary material, which is available to authorized users.

A. S. Devonshire $(\bowtie) \cdot$ A. S. Whale $\cdot$ A. Gutteridge $\cdot$ G. Jones

C. A. Foy $\cdot$ J. F. Huggett

Molecular and Cell Biology Team, LGC Ltd, Queen's Road,

Teddington TW11 0LY, UK

e-mail: alison.devonshire@lgcgroup.com

S. Cowen

Statistics Team, LGC Ltd, Queen's Road, Teddington TW11 0LY, UK measurement of some target genes (e.g. TERT) were, on average, more than twofold higher than those of other assays (e.g. ERV3). We conclude that analysis and averaging of multiple reference genes using a GeNorm approach gives a more reliable estimate of total cfDNA quantity.

Keywords Cell-free DNA - Circulating nucleic acids . Clinical/biomedical analysis - Diagnostics · Liquid biopsy $\cdot$ Reference materials

\section{Introduction}

The discovery of cell-free DNA (cfDNA) in blood has provided an accessible source of genetic material from foetal tissue [1], solid tumours [2,3] or solid organ transplants [4]. Owing to the relative ease of access and the minimally invasive nature of the sampling, cfDNA could be used to simplify the longitudinal monitoring of disease progression or response to treatment in cancer patients [5], where the term 'liquid biopsy' has emerged to describe blood-based monitoring of tumour genetics [6]. Analysis of cfDNA also provides a safer alternative to amniocentesis or chorionic villus sampling for prenatal diagnostics [7], or to organ biopsy for the detection of transplant rejection [8]. Currently, measuring somatic mutations, such as those observed in the Kirsten rat sarcoma viral oncogene homologue gene (KRAS) [9], and copy number variations, such as human epidermal growth factor receptor 2 (ERBB2, formerly known as HER2) amplification in breast cancer [10] or foetal aneuploidy [11] in cfDNA, show considerable clinical potential.

One of the main hindrances in using cfDNA as a robust analyte is a lack of standardisation and appropriate controls in this field as highlighted by a number of comprehensive reports $[6,12-14]$. These reviews attribute a lack of comparability 
between results to differences in sample processing methods and storage conditions, and in techniques for both the extraction and quantification. Recently, progress has been made in better definition of factors influencing preanalytical sample processing and storage [15-17], but variability between extraction methods and quantification approaches still presents major potential sources of experimental error [18]. In our study, we therefore focussed on the latter two aspects of cfDNA analysis.

Circulating cfDNA is a challenging analyte for extraction owing to its low concentration in plasma in normal individuals (in the region of $1.8-44 \mathrm{ng} / \mathrm{mL}$ ), although this can be increased greatly in diseased or pregnant individuals [12]. Many laboratories have evaluated and compared a number of different extraction methods for the isolation of cfDNA from plasma and have demonstrated that the extraction can differ considerably in terms of efficiency depending on the method [18-26]. Historically, many of the extraction methods used in cfDNA studies, such as the QIAamp ${ }^{\circledR}$ DNA blood mini (DBM) kit and the QIAamp DSP virus kit (both from QIAGEN), were developed initially to extract high-integrity genomic DNA from blood cells or virions, and not for highly fragmented cfDNA $[20,25,27,28]$. This could be responsible for the noted inefficiency in some extraction methods published. Although cfDNA is fragmented by nature and is present in normal individuals, tumour-derived cfDNA can differ in fragment size profile depending on the cellular process causing its release into the circulation [29, 30]. Furthermore, fetalderived cfDNA is often more fragmented than maternal cfDNA, requiring separation approaches in order to improve recovery of the fetal-derived fraction [31].

In addition to characterisation of extraction recovery, quantification of the total amount of cfDNA is important in order to define what fraction of the total is composed of the tumour- or fetal-derived DNA. This fraction is required in non-invasive prenatal diagnosis for the calculation of the relative chromosome dosage for assessment of fetal aneuploidies [32] or relative mutation dosage approaches for single-gene disorders such as sickle cell anaemia [33], as well as tumour diagnostics for monitoring of cancer-associated copy number variations [10]. The low concentration of cfDNA extracts makes quantification of yield using methods such as UV spectroscopy or fluorescence spectroscopy problematic [34]. Assays based on quantitative PCR (qPCR) are often used for measurements of cfDNA [12]. However, qPCR also has increased variability at lower copy numbers [35], which may lead to further imprecision and bias being introduced at the quantification stage.

The emergence of kits onto the market which are specifically developed for cfDNA isolation may aid in the robustness and reproducibility of cfDNA extractions. These kits include, but are not restricted to, the QIAamp circulating nucleic acid (CNA) kit (QIAGEN), the NucleoSpin ${ }^{\circledR}$ Plasma XS (NS) kit (Macherey-Nagel) and the FitAmp ${ }^{\mathrm{TM}}$ plasma/serum DNA isolation (FA) kit (Epigentek). We present a comparison study of three specific cfDNA extraction methods with the established DBM kit. To monitor the extraction efficiency, linearity of the extraction yield, presence of co-purified inhibitors and bias associated with fragment size, we developed an in-house artificial spike-in material containing small (approximately $100 \mathrm{bp}$ ), medium (approximately $500 \mathrm{bp}$ ) and large (approximately 1,500 bp) fragment sizes. Finally, we investigate how reliable the measurement of endogenous genes is for quantification of total cfDNA in terms of bias and precision by comparing measurements of seven genomic loci in 17 individual plasma samples by qPCR and digital PCR (dPCR).

\section{Materials and methods}

Fragmentation of $A D H$ plasmid

The pSP64 poly(A) plasmid containing the Arabidopsis thaliana alcohol dehydrogenase gene $(A D H)$ fragment (GenBank ID M12196) was linearised with $B g l I$ as described previously [36]. The $4.5-\mathrm{kb}$ linearised plasmid was fragmented in a double digest containing $A l w \mathrm{NI}, B s r \mathrm{DI}$ and bovine serum albumin to give six fragments of various sizes $(67,115,461,530,1,448$, and 1,889 bp). Complete linearisation and fragmentation was confirmed using a 2100 bioanalyzer and DNA 7500 series II kit (Agilent, South Queensferry, UK) according to the manufacturer's instructions (Fig. S1).

\section{Human plasma samples}

Plasma samples from 17 individual donors $\left(20 \mathrm{~mL}\right.$ EDTA-K $\mathrm{K}_{2}$ treated plasma per donor) were purchased from SeraLab and stored on arrival at $-80^{\circ} \mathrm{C}$. Female donors, aged $50-59$ years (median donor age of 53.1 years), were from Caucasian, black or Hispanic backgrounds (Table S1). Samples were thawed prior to pooling or DNA extraction, and residual cellular debris was removed using centrifugation at 5,000 rpm for $3 \mathrm{~min}$ as previously described [37]. Two pools of plasma samples were prepared: plasma pools A (i) and A (ii) were prepared by mixing $8 \mathrm{~mL}$ from each donor sample numbered $1-5(n=2)$, and plasma pool B was prepared by mixing $11 \mathrm{~mL}$ from each donor sample numbered 6-17 $(n=1)$ (Table S1). Sample pools were homogenised by mixing them on a SpiraMixer at $4{ }^{\circ} \mathrm{C}$ for $30 \mathrm{~min}$. The fragmented $A D H$ plasmid was added to a $15-\mathrm{mL}$ subaliquot of plasma pool A (i) as an extraction control at $10^{6}$ copies per millilitre of plasma [designated as "plasma pool A (i) $+A D H$ "], following which further homogenisation of the plasma subpool was performed by rotation on a SpiraMixer at $4{ }^{\circ} \mathrm{C}$ for $30 \mathrm{~min}$. All plasma pools were stored in aliquots [plasma pools A (i) and A (ii), 
$1.1 \mathrm{~mL}$ (all aliquots); plasma pool B, $1 \times 35 \mathrm{~mL}, 2 \times 45 \mathrm{~mL}]$ at $-80{ }^{\circ} \mathrm{C}$.

\section{DNA extraction}

Four DNA extraction kits were used for comparison: QIAamp CNA kit (QIAGEN), QIAamp DBM kit (QIAGEN), NS kit (Macherey-Nagel) and FA kit (Epigentek). Replicate extractions were performed with plasma pool A (i) $(n=6)$ and plasma pool A (i) $+A D H[n=4 ; n=3$ (DBM kit)]. One millilitre of plasma was processed per extraction with the CNA and DBM kits and $0.5 \mathrm{~mL}$ plasma was processed with the NS and FA kits in line with the manufacturers' recommended input ranges. For the CNA kit, samples were processed according to the manufacturer's protocol for 1-mL input volume with an elution volume of $50 \mu \mathrm{L}$. For the DBM kit, cfDNA was extracted from plasma as described by Fleischhacker et al. [18] in spin-column format with an elution volume of $50 \mu \mathrm{L}$. For the NS kit, the high-sensitivity protocol was followed, including the optional proteinase digestion stage, with an elution volume of $20 \mu \mathrm{L}$. For the FA kit, the standard protocol was followed with an elution volume of $18 \mu \mathrm{L}$. Extracts were made up to final volumes of $200 \mu \mathrm{L}$ (CNA and DBM kits) and $100 \mu \mathrm{L}$ (NS and FA kits) with nuclease-free water, giving a final equivalent concentration of $5 \mu \mathrm{L}$ plasma per microlitre of extract for all samples.

To assess inhibition of qPCR by components of cfDNA extracts, the two kits with the possibility of producing the maximum concentrations of cfDNA in the eluate were selected: the CNA and NS kits. Extractions were performed with plasma pool A (ii). For the CNA kit, three extractions were performed with $5 \mathrm{~mL}$ plasma and an elution volume of $20 \mu \mathrm{L}$, followed by pooling (final concentration equivalent to $1,250 \mu \mathrm{L}$ plasma per microlitre of extract). For the NS kit, six replicate extractions were performed with $0.6 \mathrm{~mL}$ plasma and an elution volume of $10 \mu \mathrm{L}$, followed by pooling (final concentration equivalent to $300 \mu \mathrm{L}$ plasma per microlitre of extract). Subsequently, dilutions were prepared in nucleasefree water.

For investigation of the linearity of extraction efficiency, plasma input volumes of 1, 2, 3 and $5 \mathrm{~mL}(n=3)$ from plasma pool B were processed with the CNA kit, which has the largest range of possible plasma input volumes of the kits tested, and were eluted in $50 \mu \mathrm{L}$ elution buffer. Three independent sets of extractions were performed. Extracts were analysed undiluted by qPCR (equivalent to $20 \mu \mathrm{L}$ plasma per microlitre of extract).

Two sets of DNA extractions from 17 individual donor plasma samples were performed with $1 \mathrm{~mL}$ plasma using the CNA kit with elution volumes of $50 \mu \mathrm{L}$ (Fig. 5) and $20 \mu \mathrm{L}$ (Figs. 6, 7). The smaller final volume was used to increase the cfDNA concentrations in extracts for dPCR analysis. For qPCR analysis, extracts were diluted to the equivalent $25 \mu \mathrm{L}$ plasma per microlitre of extract.
Real-time qPCR

Real-time qPCR assays for human genomic targets telomerase reverse transcriptase (TERT) and ribonuclease P RNA component H1 (RPPH1) were designed using Primer Express ${ }^{\circledR}$ (Applied Biosystems). Additional assays for human genomic targets $A L U J$ [38], endogenous retrovirus group 3 (ERV3) [28], glyceraldehyde 3-phosphate dehydrogenase (GAPDH) [39] and $N$-acetylglucosamine kinase $(N A G K)$ [40] were based on previous publications. A commercial assay ValidPrime $^{\mathrm{TM}}(\mathrm{VP})$ designed to a non-transcribed genomic locus present at one copy per haploid normal genome was obtained from TATAA Biocenter (Göteborg, Sweden). Sequences present in the $A D H$ plasmid insert sequence were quantified using $A d h \beta$ and $A d h \delta$ assays [36] or an assay for the 115-bp fragment of the plasmid backbone ' $A D H-115 \mathrm{bp}$ ' (Fig. S1) designed using Primer Express. Detailed information relating to PCR assays is provided in Table S2. All qPCR experiments were performed in accordance with the MIQE guidelines [35] (Table S3, part A).

Triplicate qPCR assays were performed for each point of the standard curve, and test samples were assessed in single reactions, unless stated otherwise in the figure legends. For the endogenous targets and $A L U J$ assays, a seven-point fivefold dilution series (from approximately 3,042 to approximately 0.2 haploid genome copies per reaction) of female human genomic DNA (Promega) prepared in yeast transfer RNA (50 $\mathrm{ng} / \mu \mathrm{L}$ ) (Sigma) diluent was used for generation of the standard curve. $A L U$ is a repetitive sequence found at high copy number in the genome [41, 42], and so the standard curve was generated as genome equivalents rather than copies as for the other genomic targets. To assess recovery of the exogenous spike-in from cfDNA extractions, a four-point tenfold dilution series (from 50,000 to 50 copies per reaction) of the fragmented $A D H$ plasmid (diluent, nuclease-free water) was used to measure the number of copies of each $A D H$ plasmid fragment. $A D H-$ $115 \mathrm{bp}, A d h \beta$ and $A d h \delta$ assays were used to measure the recovery of the 115-, 461- and 1,448-bp $A D H$ plasmid fragments, respectively. Assessment of qPCR inhibition of the $A d h \beta$ assay by cfDNA extracts using the CNA, NS and FA kits (without addition of the $A D H$ plasmid before extraction) was performed using the same dilution series of $A D H$ plasmid in the presence of $5 \mu \mathrm{L}$ cfDNA extract and qPCR efficiency determined on the basis of the slope of the linear regression analysis of quantification cycle $\left(C_{\mathrm{q}}\right)$ versus concentration (copies per reaction).

To further assess inhibition of qPCR by components of cfDNA extracts prepared using the CNA and NS kits, fragmented $A D H$ plasmid (500 copies) was added to each $A d h \beta$ assay in addition to $5 \mu \mathrm{L}$ of concentrated or diluted cfDNA extract, and $C_{\mathrm{q}}$ values were compared with the control condition (absence of cfDNA extract). 
For all experiments unless otherwise stated, $20-\mu \mathrm{L}$ reactions containing $5 \mu \mathrm{L}$ sample were performed using universal master mix or gene expression master mix (Table S2) and the 7900HT fast real-time PCR system (all Life Technologies). For all experiments, no-template controls were performed with the addition of diluent without cfDNA extract or $A D H$ plasmid. Results for the no-template controls are given in Table S4. The thermal cycling conditions were as follows: $50{ }^{\circ} \mathrm{C}$ for $2 \mathrm{~min}, 95^{\circ} \mathrm{C}$ for $10 \mathrm{~min}, 40$ cycles of $95^{\circ} \mathrm{C}$ for $15 \mathrm{~s}$ then $60{ }^{\circ} \mathrm{C}$ for $60 \mathrm{~s}$. For the $A L U J$ assays, $20-\mu \mathrm{L}$ reactions containing $5 \mu \mathrm{L}$ sample were performed using Power SYBR ${ }^{\circledR}$ Green master mix (Life Technologies) using the same cycling conditions as mentioned above with the addition of a melting step at the end to check the dissociation curve for the presence of primer-dimers and non-specific products: $95{ }^{\circ} \mathrm{C}$ for $15 \mathrm{~s}$, $60{ }^{\circ} \mathrm{C}$ for $15 \mathrm{~s}$ followed by an increase in temperature to $95^{\circ} \mathrm{C}$ at a ramp rate of $2 \%$. SDS version $2.4(\mathrm{ABI})$ was used to calculate $C_{\mathrm{q}}$, which is defined as the number of cycles at which the fluorescence signal is significantly above the threshold. Data were exported for further analysis in Microsoft Excel $^{\circledR}$ 2003/2007.

\section{Droplet dPCR}

The details and sequences of the dPCR assays were identical to those used in real-time qPCR experiments (Table S2). Digital PCR (dPCR) experiments using the QX100 ${ }^{\mathrm{TM}}$ Droplet Digital $^{\text {TM }}$ PCR system (Bio-Rad) were performed in accordance with the dMIQE guidelines [43] (Table S3, part B). Final-volume reactions of $20 \mu \mathrm{L}$ containing ddPCR ${ }^{\mathrm{TM}}$ supermix (Bio-Rad) and $3.5 \mu \mathrm{L}$ sample were established prior to droplet formation using the QX100 droplet generator according to the manufacturer's instructions. Briefly, each $20-\mu \mathrm{L}$ reaction mixture was pipetted into the sample well of a DG8 cartridge with $70 \mu \mathrm{L}$ generator oil pipetted into the oil well. Droplets were generated by the QX100 droplet generator, and $40 \mu \mathrm{L}$ of droplets was transferred, using a multichannel pipette, into a 96-well plate. Each plate was sealed with foil using a PX1 ${ }^{\mathrm{TM}}$ PCR plate sealer, and PCR was performed using a $\mathrm{C} 1000$ Touch $^{\mathrm{TM}}$ thermal cycler. The thermal cycling conditions were as follows: $95{ }^{\circ} \mathrm{C}$ for $10 \mathrm{~min}, 40$ cycles of $94{ }^{\circ} \mathrm{C}$ for $30 \mathrm{~s}$ then $60^{\circ} \mathrm{C}$ for $30 \mathrm{~s}$ followed by $98{ }^{\circ} \mathrm{C}$ for $10 \mathrm{~min}$ and cooling to $4{ }^{\circ} \mathrm{C}$. Droplets were analysed using the QX100 droplet reader according to the manufacturer's instructions. Data were analysed using QuantaSoft ${ }^{\mathrm{TM}}$ version 1.3.2.0 to count the number of positive droplets $(m)$ and the total number of accepted droplets $(n)$. The mean number of copies per droplet $(\lambda)$ was estimated using the relationship $\lambda=-\ln (1$ $-m / n)$, which assumes a Poisson distribution for the number of copies in each droplet (Table S5) [43, 44]. Data were exported for further analysis into Microsoft Excel 2003/2007. The number of template copies per microlitre was calculated using the published manufacturer's volume of $0.91 \mathrm{~nL}$ per droplet, and confidence intervals were calculated as described previously [45]. For all experiments, notemplate controls were established in parallel with diluent added without cfDNA extract (Table S5).

Data analysis

Data were analysed in Microsoft Excel 2003/2007 and Graphpad Prism ${ }^{\circledR}$ version 5.04. All data were converted to the number of copies per millilitre of plasma, where one copy is either for the single gene measured or as a single human haploid genome that is calculated as $3.3 \mathrm{pg}$. Reference gene stability of seven reference genes in the group of 17 donors (Fig. 5) was analysed using the GeNorm algorithm in GenEx Enterprise version 5.3.6 (MultiD Analyses, Göteborg, Sweden) [46].

One- and two-way analysis of variance (ANOVA) tests (Figs. 1, 2, 3, 4b), regression analysis (Fig. 4a) and Pearson correlation analysis (Table S5) were performed using Graphpad Prism version 5.04. Analysis of reference gene copy numbers in cfDNA extracts (Figs. 5, 6, 7) was performed with $\log _{10}$-transformed values in $\mathrm{R}$ version 3.0.1 [47] using linear models, with the reference gene and the donor as fixed variables. Two-way ANOVA was performed, and differences between reference genes were compared using Tukey's honest significant difference test (see the electronic supplementary material). Further information is given in the electronic supplementary material.

An average cfDNA quantity for each donor based on TERT, RPPHI and ERV3 copy numbers (GeNorm approach) was calculated as the arithmetic mean of $\log _{10}$-transformed values. We calculated $95 \%$ confidence intervals of the GeNorm average cfDNA quantity on the basis of errors

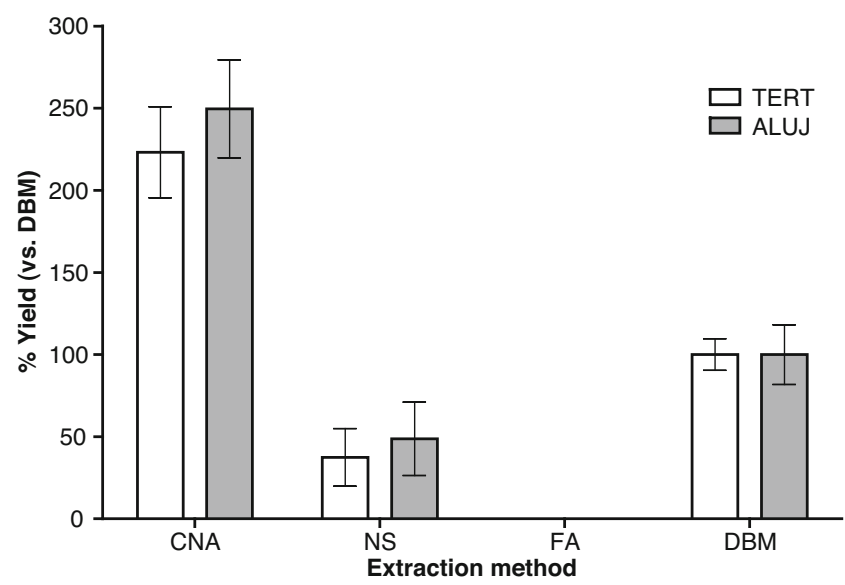

Fig. 1 Assessment of cell-free DNA (cfDNA) yield using four extraction methods. The mean yield \pm one standard deviation from replicate extractions using plasma pool A (i) (with or without $A D H$ ) performed with the QIAamp circulating nucleic acid $(C N A)$, NucleoSpin Plasma XS $(N S)$ and FitAmp plasma/serum DNA isolation $(F A)$ kits $(n=10)$ and the QIAamp DNA blood mini $(D B M)$ kit $(n=9)$ is displayed relative to the mean yield of the DBM kit. The yield of cfDNA was quantified by quantitative PCR (qPCR) assays to TERT and $A L U J$ 


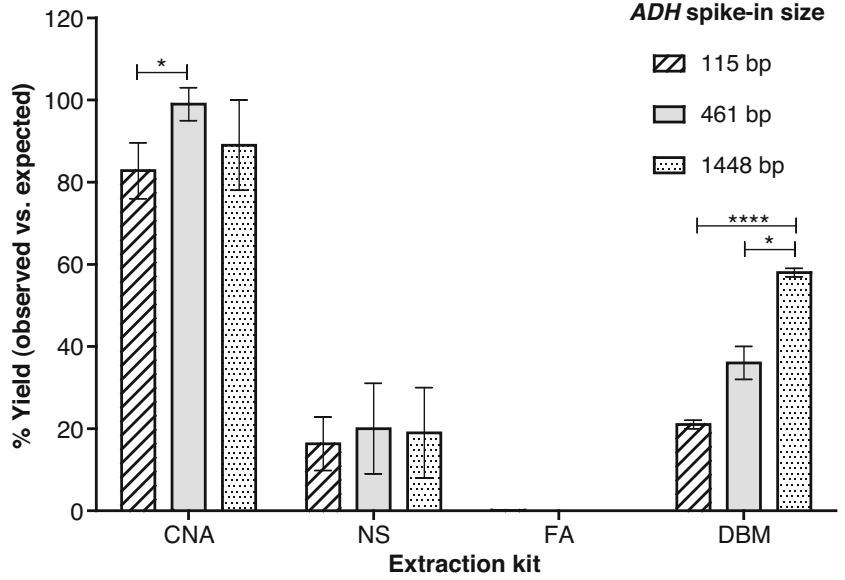

Fig. 2 Assessment of extraction efficiency and fragment size bias of four extraction methods using an exogenous spike-in. Extraction efficiencies of the CNA, NS, FA and DBM kits are expressed as a percentage of input $\left(10^{6}\right.$ copies per millilitre of plasma $) \pm$ one standard deviation $(n=3$ extractions for the DBM kit, $n=4$ extractions for the other methods) for 115-, 461- and 1,448-bp fragments of the $A D H$ plasmid spike-in. Significant differences between the yields of the $A D H$ plasmid fragments are indicated: one asterisk, $p<0.05$; four asterisks, $p<0.0001$

associated with the reference gene and qPCR replicate by oneway ANOVA (Graphpad Prism) (see the electronic supplementary material). The mean square between-group $\left(\mathrm{MS}_{\mathrm{r}}\right)$ variance was used to calculate the standard error of the mean $\sigma$ :

$\sigma^{2}=\frac{\mathrm{MS}_{\mathrm{r}}}{n b}$

where $b$ is the number of groups (reference genes) and $n$ is the number of replicate qPCR measurements. The $95 \%$ confidence interval was calculated by multiplying the standard error $\sigma$ by the coverage factor $k$ associated with two degrees of freedom (three groups) for $\alpha=0.05(k=4.3)$. The logtransformed values were transformed to linear scale (Fig. 7).

\section{Results}

We compared three kits specifically developed for the extraction of cfDNA from body fluids (CNA, NS and FA kits) with the DBM kit (which has been used widely for this application [18]) using plasma pool A (i). The yields of cfDNA in terms of genome equivalents per millilitre of plasma for each of the four methods were assessed by qPCR measurement of two reference assays, one for the single-copy gene TERT, and the other for the genomic repetitive element (ALUJ). The values are expressed as percent yield compared with the mean yield of the DBM kit (Fig. 1). The results were consistent between both reference assays and suggested that the yield of cfDNA per millilitre of plasma was between 2.2-fold and 2.5-fold higher with the CNA kit than with the DBM kit, whereas the
NS extracts contained less than half the cfDNA yield of the DBM extracts. Extracts obtained using the FA kit contained very low levels of cfDNA, which were not detectable by the TERT assay and were estimated to contain approximately one genome copy per millilitre of plasma by the ALUJ assay (Fig. 1).

To investigate further extraction kit DNA recovery and DNA fragment bias, a spike-in containing the digested $A D H$ plasmid was added to a subpool of plasma prior to isolation of cfDNA [plasma pool A (i) + ADH]. The recovery of the 115-, 461- and 1,448-bp fragments was measured after extraction using three qPCR assays detecting sequences present in these fragments ( $A D H-115 \mathrm{bp}, A d h \beta$ and $A d h \delta$, respectively) in order to evaluate the fragment size profile of the extraction methods (Fig. 2).

In line with the results from the endogenous targets (Fig. 1), the extraction efficiency of the CNA kit was the highest of the four methods, with over $80 \%$ recovery for all three fragment sizes. Average approximately twofold and approximately 4.8fold lower extraction efficiencies were noted for the DBM and NS methods, respectively (Fig. 2). For the FA kit, recovery of the exogenous DNA was also lower (less than $0.1 \%$ recovery of all three $A D H$ fragments). The NS kit demonstrated an even profile in terms of recovery of both smaller and larger DNA fragments. Although the CNA kit recovered a high percentage ( $83 \%$ ) of the smallest plasmid fragment (115 bp), the yield of this was not as high as that of the 461-bp fragment (99\%) $(p<0.05)$. The DBM kit demonstrated the highest recovery of the largest, 1,448-bp fragment (58\%), compared with $37 \%$ recovery of the 461 -bp fragment $(p<0.05)$ and $21 \%$ recovery of the 115-bp fragment $(p<0.0001)$. The repeatability associated with replicate extractions for each kit was consistent between the results of endogenous and plasmid targets, with the CNA and DBM kits demonstrating a mean repeatability percent coefficient of variation (CV) of $10 \%$ for all assays, compared with $49 \%$ for the NS kit (Table S6) (data not presented for the FA kit owing to the low yield).

One advantage of the CNA and NS kits is the ability to concentrate cfDNA, through the use of either large collection tubes for processing up to $5 \mathrm{~mL}$ plasma (CNA kit) or a specially designed purification column allowing elution volumes as low as $5 \mu \mathrm{L}$ (NS kit). These more concentrated extracts are ideally suited for new technologies such as dPCR, which typically use smaller volumes of samples per assay compared with qPCR $[45,48]$. However, these highly concentrated extracts may also contain higher concentrations of PCR inhibitors present in the extraction matrix (such as blood tube preservatives [49]). To investigate this, replicate extractions were performed using plasma pool A (ii) with the maximum plasma input volume of the two kits $(5 \mathrm{~mL}$ for the CNA kit and $0.6 \mathrm{~mL}$ for the NS kit) together with the minimum elution volumes ( 20 and $10 \mu \mathrm{L}$, respectively), followed by pooling after extraction before serial dilution to test whether 
a

CNA (Adh $\beta$ probe-based assay)

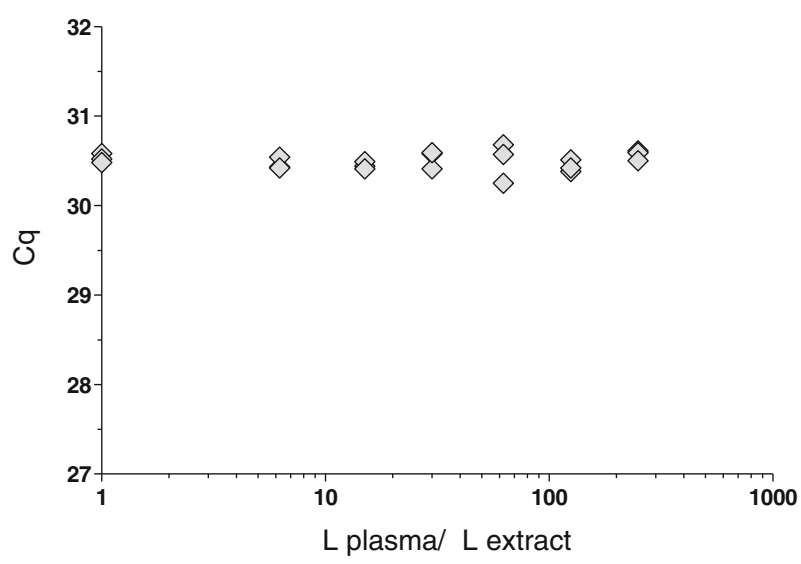

C

CNA (Adh $\beta$ SYBR-based assay)

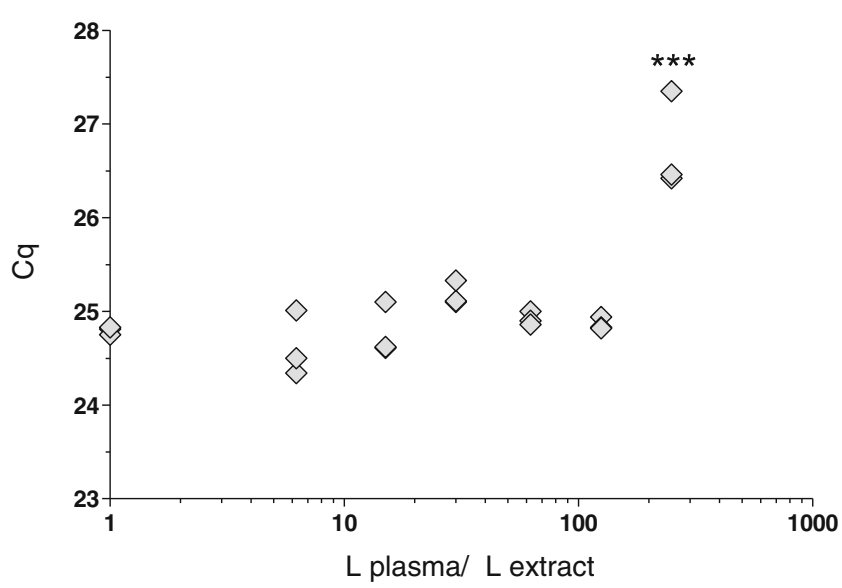

Fig. 3 Assessment of qPCR inhibition by cfDNA extracts using two different extraction methods. Fragmented $A D H$ plasmid (500 copies per reaction) was measured using the $A d h \beta$ assay (qPCR, $n=3$ ) in both hydrolysis probe $(\mathbf{a}, \mathbf{b})$ and intercalating dye $(\mathbf{c}, \mathbf{d})$ assay formats in the presence of increasing concentrations of cfDNA extract produced using

the concentrated extracts inhibited qPCR (Fig. 3). Inhibitory substances in the extracts were assayed by spiking the qPCR with $A D H$ plasmid and measuring $C_{\mathrm{q}}$ using the $\operatorname{Adh} \beta$ assay. The assay was performed in two formats with either a hydrolysis probe (Figs. 3a, b, S2) or using intercalating dye chemistry (Fig. $3 \mathrm{c}, \mathrm{d}$ ). An increase in $C_{\mathrm{q}}$ versus the control reaction was judged to indicate inhibition of the qPCR. Reactions contained $4 \mu \mathrm{L}$ sample with concentrations equivalent to $6.25,15,30$ and $60 \mu \mathrm{L}$ plasma per microlitre for the CNA and NS kits, and additionally 125 and $250 \mu \mathrm{L}$ plasma per microlitre in the case of the CNA kit. The TaqMan-based $A d h \beta$ assay did not show any evidence of inhibition with extracts from either the CNA (Fig. 3a) or the NS (Fig. 3b) extracts. The CNA kit extracts did not inhibit the SYBR-based $A d h \beta$ assay up to concentrations of $125 \mu \mathrm{L}$ plasma per microlitre; however, at the maximum concentration of $250 \mu \mathrm{L}$ plasma per microlitre of extract (equivalent to $1 \mathrm{~mL}$ plasma extract per qPCR), a mean shift of approximately 2.0 b

NS (Adh $\beta$ probe-based assay)

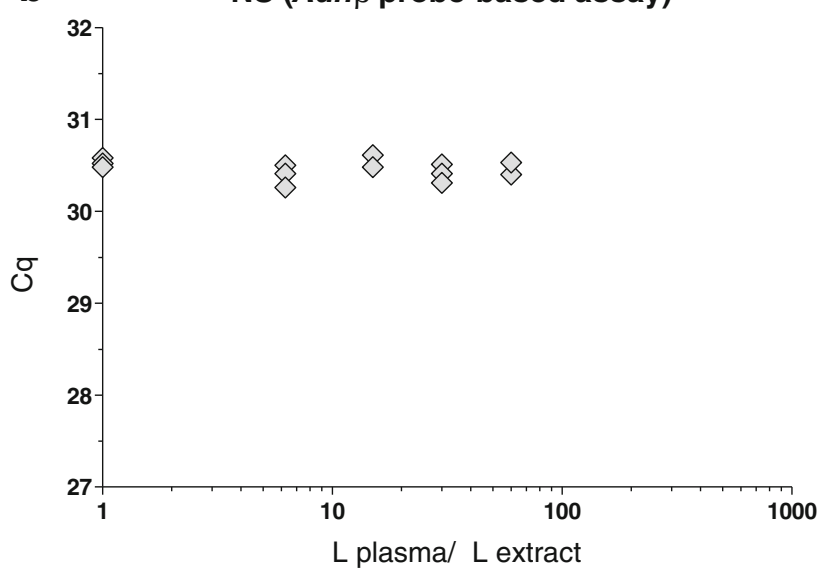

d

NS (Adh $\beta$ SYBR-based assay)

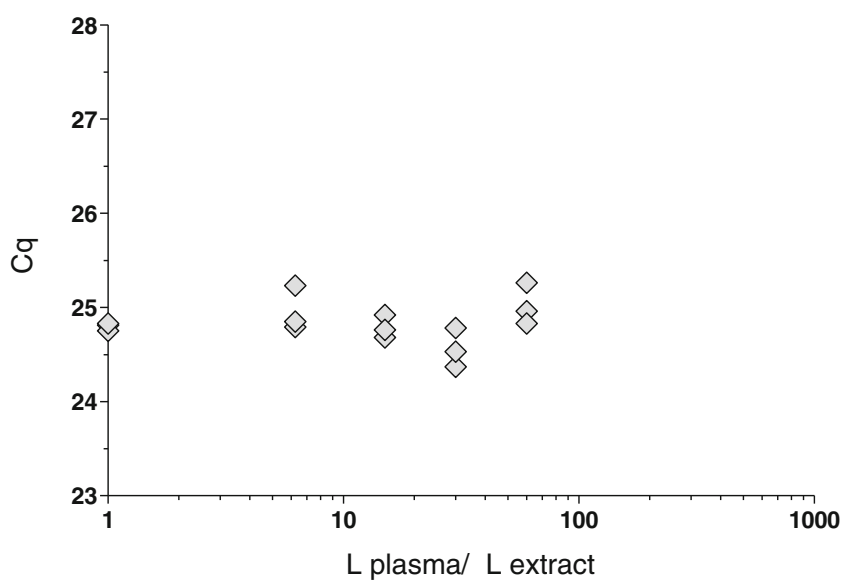

the CNA (a, c) and NS (b, d) kits and compared with control conditions (given a nominal concentration of $1 \mu \mathrm{L}$ plasma per microlitre of extract owing to plotting on a log scale). Individual data points represent replicate qPCR assays. An increase in $C_{\mathrm{q}}$ indicates inhibition of qPCR versus the control condition. Three asterisks, $p<0.001$

$C_{\mathrm{q}}$ units was observed (Fig. 3c). The NS kit extracts did not inhibit the SYBR-based $A d h \beta$ assay (Fig. 3d).

On the basis of the results of the assessments of yield, fragment size distribution and presence of inhibitors (Figs. 1, 2, 3), the CNA kit was chosen as the most suitable extraction method for high-sensitivity cfDNA analysis. We further evaluated the performance of this kit in terms of linearity of yield and within-laboratory reproducibility (intermediate precision). Plasma can be processed using this kit with input volumes between 1 and $5 \mathrm{~mL}$, and so we tested whether the cfDNA yield was proportional to the plasma input volume by performing independent extractions of plasma pool B with $1,2,3$ or $5 \mathrm{~mL}$ plasma ( $n=3$ replicates per experiment) on three different days and with elution in a fixed volume. The yield of cfDNA was assessed using the TERT assay (Fig. 4). Log-transformed cfDNA yields in the CNA extracts were normally distributed (analysis not shown) and were linear with respect to input volume up to an input volume of $3 \mathrm{~mL}$ plasma 

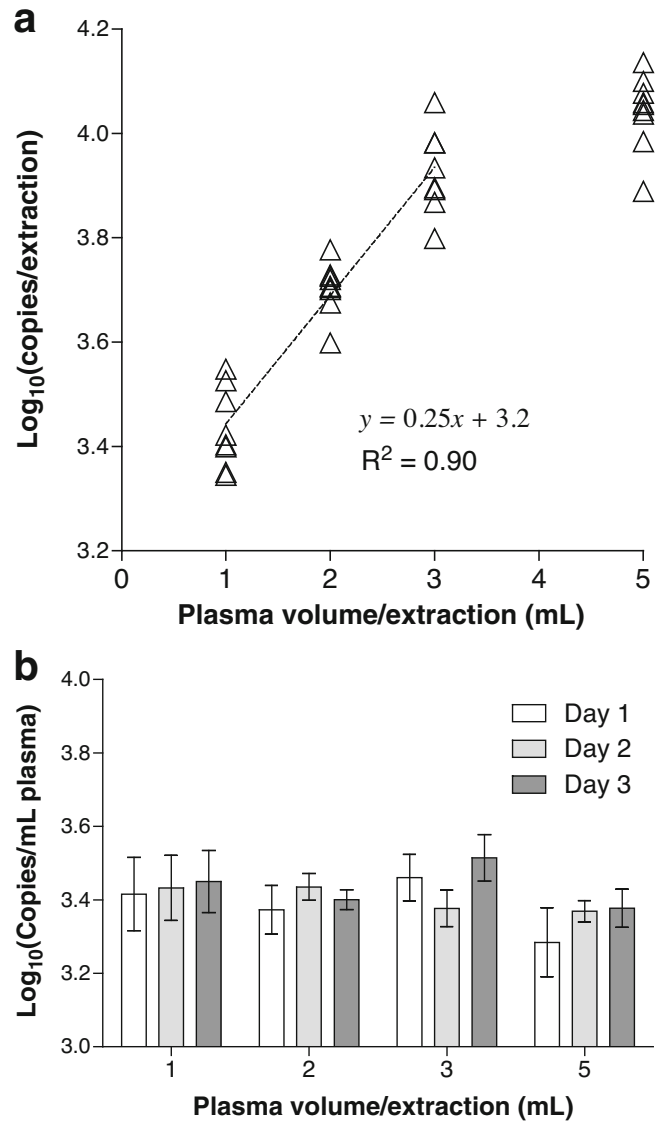

Fig. 4 Linearity and within-laboratory reproducibility of cfDNA extraction using a single method. Three independent extraction experiments performed on different days using the CNA kit were performed with 1,2, 3 and $5 \mathrm{~mL}$ plasma pool B ( $n=3$ replicates per day). a The yield of cfDNA (copies per extraction) is compared with the volume of plasma $(\mathrm{mL})$ processed per extraction using the CNA kit ( $n=9$ per volume). Data points correspond to individual extracts. $\mathbf{b}$ The within-laboratory reproducibility of extract yield per millilitre of plasma is compared for different input volumes and three independent experiments. Mean values \pm one standard deviation are plotted for each day $(n=3)$

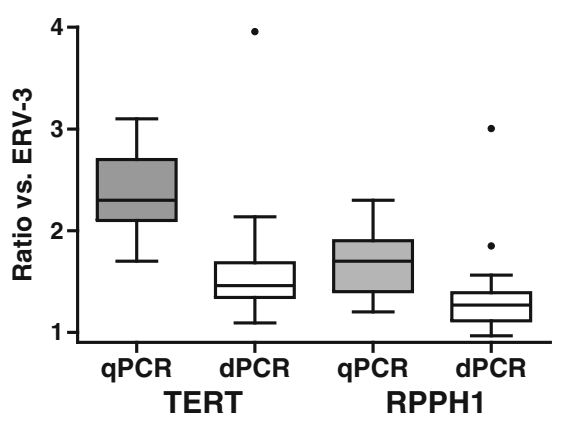

Fig. 6 Comparison of fold differences between reference genes measured by qPCR and droplet digital PCR $(d P C R)$. The ratios of TERT/ $E R V 3$ and RPPH1/ERV3 genomic copy numbers in extracts from 17 plasma samples are compared for qPCR-based and droplet-dPCR-based measurements. Box and whisker plots depict the median value (line), interquartile range (box) and upper and lower limits (whiskers) based on Tukey's honest significant difference test. Outlier values are indicated as single points

per extraction $\left(R^{2}=0.90\right)$ (Fig. 4a). Yield expressed as per millilitre of plasma was found to be significantly different between the four different input volumes on the basis of ANOVA $(p=0.015)$. This is consistent with the regression analysis (Fig. 4a), and suggests a slight reduction in extraction efficiency at $5 \mathrm{~mL}$ plasma per extraction (Fig. 4b). However, post hoc analysis did not indicate significant differences between specific volumes (data not shown). No significant differences in yield per millilitre of plasma were found between the three independent extractions (Fig. 4b). The withinlaboratory reproducibility was calculated as a $\mathrm{CV}$ of $17 \%$, composed predominantly of within-day variability (16\%), which was consistent with repeatability data using $1 \mathrm{~mL}$ plasma per extraction (Fig. 1, Table S6).

Having assessed different technical aspects of the performance of cfDNA extraction methods, we investigated controls for the quantification of cfDNA extraction and downstream
Fig. 5 Comparison of cfDNA copy number of seven different reference genes in 17 donor samples measured by qPCR assays. The results for each reference gene are displayed with a different symbol for each target

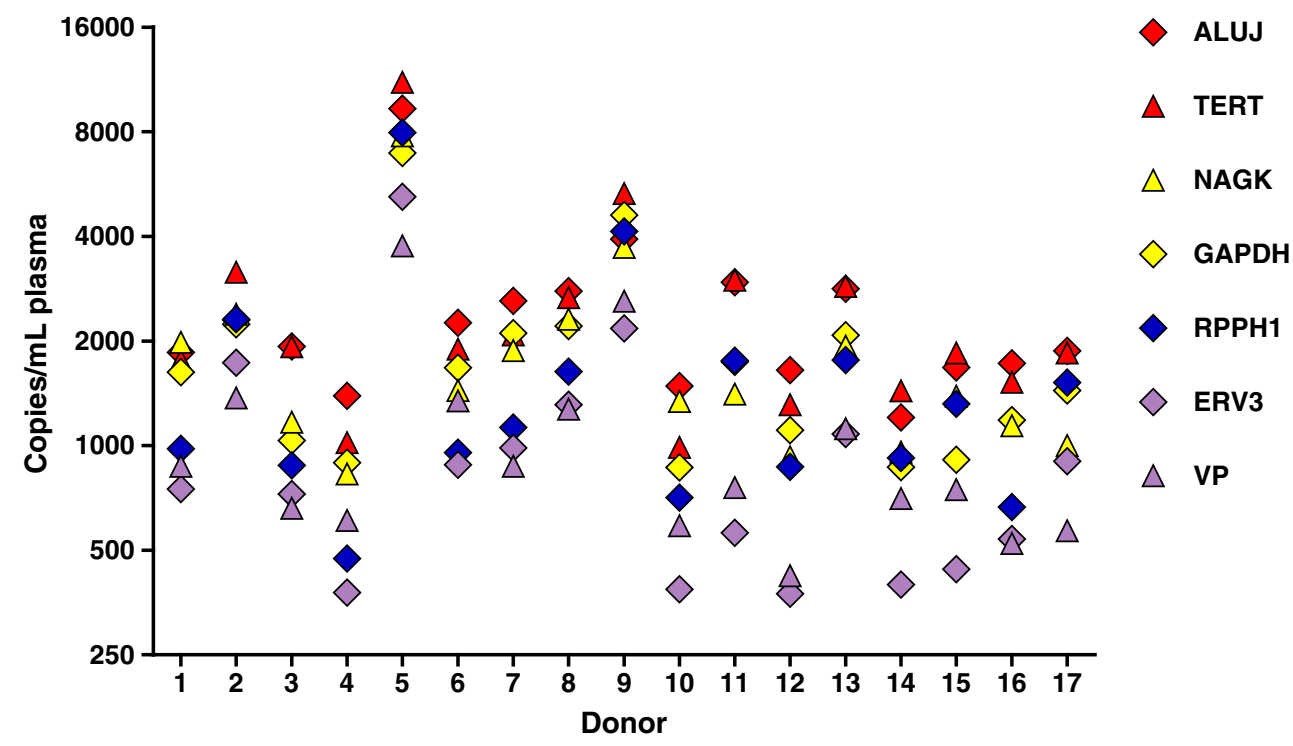


Fig. 7 Comparison of a multiple reference gene approach for plasma cfDNA quantification with single gene measurements. The $95 \%$ confidence interval (grey area) associated with a normalised geometric average cfDNA quantity calculated on the basis of three reference genes (TERT, RPPH1, ERV3) and three independent qPCR experiments is compared with mean estimates for each of the above-mentioned reference genes and $A L U J$ for each donor

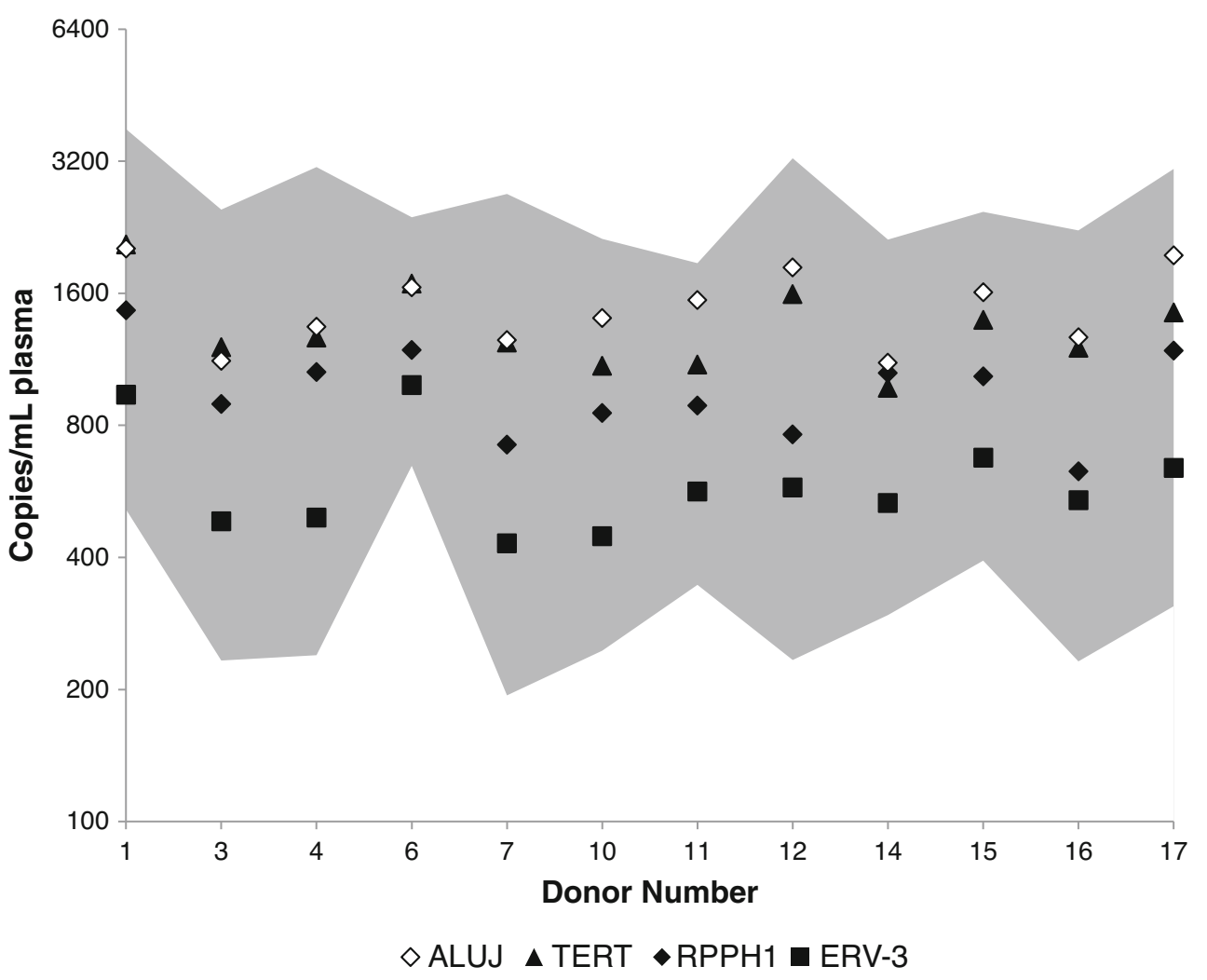

assay normalisation to total cfDNA. The total cfDNA isolated from plasma samples from 17 individual donors was quantified using seven different reference assays. In addition to an assay for TERT, a number of assays for single-copy genomic targets commonly used for cfDNA measurements (RPPH1, $G A P D H, N A G K$ and ERV3) were also used, as well as a commercial assay VP, designed for an undisclosed singlecopy locus. These results were compared with the genome equivalent estimate based on measurement of the $A L U J$ repeat element.

Analysis of all seven assays demonstrated that most of the samples contained a mean of fewer than 2,500 copies per millilitre of cfDNA (equivalent to $8 \mathrm{ng} / \mathrm{mL}$ or less). However, samples from two donors (donors 5 and 9) contained larger amounts of cfDNA [mean (range) 24.6 (12.4-36.6) ng/mL and 12.5 (7.2-17.5) ng/mL, respectively] (Fig. S3). The seven assays showed strong correlation based on the donor, with correlation coefficients ( $r$ ) between 0.86 and 0.97 (Table S7). The reference genes were also analysed in terms of stability according to the GeNorm algorithm, which is commonly applied to reference gene normalisation of messenger RNA measurements [46] (Table S8). Good stability $(M)$ values were calculated for all seven assays $(M<0.4)$, suggesting all reference genes could be suitable markers of cfDNA quantity. However, absolute differences between the genomic copies were observed (Fig. 5). On the basis of linear modelling of results from all donors, copy number measurements were ranked in the following order: TERT ALUJ $>N A G K \sim$ $G A P D H>R P H H 1>E R V 3 \sim$ VP. TERT- or ALUJ-based copy number measurements were, on average, between 138 and $173 \%$ greater than those based on ERV3 or VP, whereas $R P P H 1$ copy numbers were approximately $60 \%$ higher than those of ERV3 (see the electronic supplementary material).

We speculated as to whether the discordance between individual reference gene measurements could be attributable to artefacts of the standard calibration curve. Selected samples were therefore analysed by droplet dPCR, which does not require a standard curve for absolute quantification (Fig. S4). Measurements were performed with three assays representative of high (TERT), medium (RPPH1) and low (ERV3) copy numbers. There was good agreement between the qPCR and droplet dPCR measurements of copy numbers (Fig. S5). When the results of the three different assays were compared by linear modelling, the same rank order of copies per millilitre of extract was observed as for qPCR, although the fold differences were not as large. For example, TERT and RPHH1 copy number measurements were on average $50 \%$ and $30 \%$ higher than those of ERV3 (vs $165 \%$ and $60 \%$, respectively, by qPCR) (Fig. 6; see also the electronic supplementary material).

The observed differences between qPCR and droplet dPCR, within plasma samples, demonstrate how 
quantification biases in the total cfDNA could be introduced. Calculation of an average value based on measurement of multiple reference assays was therefore investigated as a means of improving the accuracy of the cfDNA load quantification, by comparing the cfDNA load estimated by single reference gene measurements (TERT, RPHH1 and ERV3) with the mean of all three targets. Precision was calculated by performing three independent qPCR experiments with 12 of the 17 samples previously analysed (Fig. 5). Single copy loci reference gene measurements were also compared with the multicopy genomic repeat $A L U J$. For most of the samples, the apparent copy number abundances observed in the initial analysis of individual donor samples (Fig. 5) were also observed in the repeated analysis, in that ALUJ and TERT genomic copies exceeded those of RPHH1, which in turn were higher than those measured for ERV3 (Fig. 7; see also the electronic supplementary material). The arithmetic mean of the log-transformed copy number measurements for the three single-copy loci was calculated (note that this is equivalent to the geometric mean using non-log-transformed copy numbers), along with the $95 \%$ confidence interval, based on the variation between the three loci and the precision of independently replicated measurements (see "Materials and methods"). The range covered by the upper and lower limits of the expanded uncertainty occupied a central region (Fig. 7, shaded area), approximately between the higher TERT- and ALUJ-based estimates and the lower ERV3 measurements. This suggests that the mean copy number based on multiple reference genes gave a good approximation of the possible range of cfDNA genomic copies present.

\section{Discussion}

The potential of cfDNA in plasma as a source of minimally invasive material for molecular diagnostics is beginning to be realised. Several reports highlighting the lack of standardisation in this field $[12,13,50]$ and comparison of different extraction methods have begun to elucidate the impact of different methods used on the quantification of the resulting cfDNA [18-24, 26]. In this study we have investigated cfDNA standardisation by applying different strategies to the quantification of cfDNA, including an in-house artificial spike-in control material along with targeting of endogenous (reference) genes to measure total cfDNA present in a sample.

Although it is generally accepted that most of the variation observed between different individuals will be biological, there are many technical considerations that could cause a wide range of measurement discrepancies. Our data have confirmed that one of the principal causes of technical variability comes from the different isolation methods used, where the yield and efficiencies of extracted cfDNA from the same plasma samples can differ by orders of magnitude (Figs. 1, 2).
By comparing three kits designed especially for the isolation of cfDNA from plasma with the commonly used DBM extraction kit, we demonstrated that the CNA kit produced a higher yield than the other kits.

The higher yields of the CNA kit compared with the DBM kit is consistent with a recent report [19], but the DBM kit was found to be more comparable to the CNA kit by Page et al. [23], although this may be due to the different adaptations of the DBM kit for cfDNA extraction in use as the report also showed reduced cfDNA yields using the FA kit. However, by adding a plasmid spike-in control material to plasma prior to extraction, our study was able to assign a measure of extraction efficiency, further stratified by fragment size, to method performance. For the CNA kit, this suggested that nearly all $\operatorname{cfDNA}(83-100 \%)$ was recovered. The repeatability of the extraction stage was also shown to differ between methods, with the CNA and DBM kits having a CV of less than $15 \%$, whereas the repeatability of NS kit was more variable (approximately $50 \%$ ).

Further technical factors whereby extraction may influence the quality of cfDNA analysis were investigated in our study. Kits developed specifically for cfDNA analysis offer the possibility of large input and/or small elution volumes. This may compound problems associated with amplification of low copy number templates by increasing the carryover of potential inhibitors into downstream analysis methods such as qPCR. The data here demonstrated that although the two kits tested (CNA and NS kits) were capable of producing highly concentrated cfDNA extracts (up to the equivalent of $250 \mu \mathrm{L}$ plasma per microlitre of eluate and $100 \mu \mathrm{L}$ plasma per microlitre of eluate for the CNA and NS kits, respectively), alternative qPCR detection methods were affected differently by inhibitors, with the intercalating dye method less tolerant of the highest extract concentration compared with hydrolysis probe chemistry (Fig. 3). This is in agreement with our earlier observations [51].

Cell-free (cfDNA) extractions are commonly performed on $1 \mathrm{~mL}$ of plasma [18, 23]. By checking the extraction efficiency with larger plasma input volumes, we have shown that total cfDNA yield increases with increased input volumes processed using the CNA kit (Fig. 4a), at least until the maximum input volume of $5 \mathrm{~mL}$ plasma, where a small reduction in extraction efficiency may occur (Fig. 4). It is proposed that this may be due to plasma matrix components reducing flow through the column and impacting absorption of nucleic acids [24]. However, the advantage of sample concentration with larger input volumes outweighs any slight reduction in efficiency, especially for minority detection, where larger input volumes offer the possibility of improved sensitivity of detecting the minority variant [24].

It is quoted frequently that the expected amount of cfDNA from plasma in a normal human is of the order of 1,000 genome equivalents per millilitre of blood [52]. However, 
not only does this value vary considerably in the literature [12, 34], but the unit used to report the value also varies (absorption units, nangrams per millilitre of plasma, etc.) and the method used to convert one unit to another (e.g. conversion of nanograms per millilitre to genome equivalents per millilitre) is based on certain assumptions, such as uniform genome representation in a sample and $3.3 \mathrm{pg}$ as the weight of a human haploid genome. This conversion has relevance for quantification of targets present as single copies per haploid genome that are commonly used as reference genes for copy number variation assays. Such normalisation is required for detection of amplification or deletion in disease states, such as ERBB2 amplification in breast cancer [10].

Likewise, the sensitivity of techniques to measure tumourderived somatic mutations is commonly defined as a percentage of the wild-type target. Consequently, it is useful to know how many wild-type genome equivalents are present in a cfDNA sample in order to decide whether an assay is capable of measuring either the amplification of particular loci or a mutation present at $0.1 \%$ (i.e. one copy per 1,000 genome equivalents). In these instances, the measurements of a single locus may be compromised by low technical reproducibility and biases due to its overrepresentation or underrepresentation in the cfDNA. By comparing seven different assays for commonly used reference gene loci, this study has shown the resulting estimate of total genome equivalents per millilitre of plasma can vary by over twofold in magnitude within the same normal female donor (Fig. 5). This clearly demonstrates potential problems when targeting a single genomic region for estimating the abundance of cfDNA.

The droplet dPCR validation of the qPCR reference assay measurements led us to conclude that there could be both technical and biological reasons for disparity in the copy number estimates from the different reference loci observed using qPCR measurements (Fig. 5). Although the same ranking of copy number abundances was observed for the three gene targets investigated using both approaches, the magnitude of the difference was greater using qPCR compared with droplet dPCR measurements (Fig. 6). This suggests that there may be artefacts of the standard-curve-based measurements for qPCR leading to higher copy numbers being observed for some reference genes compared with others. In this study, our standard curves were based on good-quality genomic DNA as surrogate material, for cfDNA is hard to obtain. As dPCR does not need standard curves for quantification, this approach removes this potential source of bias from the data.

The similarity in ranking between qPCR and droplet dPCR measurements suggests that different loci are present at different proportions in the cell-free fraction from those present in cellular genomic DNA. Of note is that loci that are more telomeric in location (TERT and GAPDH) are more abundant than those with a more centromeric position (ERV3 and $R P P H 1)$, with $N A G K$, which is centrally located in the short arm of chromosome 2, ranked in-between. $A L U J$ is ranked level with TERT; this is consistent with the predominant telomeric location of these repetitive sequences [53]. Two recent studies using next-generation sequencing have demonstrated that the entire fetal genome can be isolated from the cfDNA in maternal plasma $[54,55]$. This demonstrates that although there may be little or no bias in the presence or absence of certain genomic sequences, a single genomic locus or element cannot necessarily meet the requirements to standardise quantitative measurement of the tumour- or fetalderived cfDNA fraction to the total cfDNA pool.

To generate a more robust method for standardised determination of the genomic content of cfDNA, this study applied the widely accepted best practice principle for gene expression analysis of multiple reference gene normalisation $[46,56]$ (Fig. 7). The GeNorm factor, or multigene average value, is the geometric mean of the copy number quantities for each of the constituent reference gene assays [46]. This is mathematically equivalent to the arithmetic mean of log-transformed quantities (as presented here). By applying the principle of GeNorm normalisation to cfDNA analysis, we calculated an average measurement that avoids a systematic overestimation or underestimation of total cfDNA load. We also outlined how the confidence interval of cfDNA load may be calculated from the contributions from reference gene variability and assay precision (based on independent qPCR measurements) and demonstrated that this approach is consistent with any of the single-gene estimates of cfDNA quantity (Fig. 7). Hindson et al. [44] also applied the principle of multiple reference gene averaging for quantification of total cfDNA for non-invasive prenatal diagnosis using four genetic loci using droplet dPCR. In this case, the contribution of each target to the overall average was weighted according to assay precision.

Calculating the confidence interval or 'measurement uncertainty' associated with total cfDNA load may help to characterise the sample prior to multiple downstream analyses (e.g. screening for several different biomarkers) and guide clinical boundaries relating to the concentration, and measurable differences, of a specific biomarker. For example, the mean and the confidence interval for total cfDNA load for donor 1 (Fig. 7) were 1,400 copies per millilitre of plasma and 500-3,800 copies per millilitre of plasma, respectively. If a mutant biomarker is present at 14 copies per millilitre, the confidence interval associated with the total cfDNA load would predict an abundance of the biomarker of between 0.4 and $2.7 \%$ (mean $1 \%$ ). Figure 7 shows our estimate of the confidence interval may be conservative, as we included reference genes with the largest difference in copy number ranking (TERT and ERV3). Using three reference genes also means that the result has two degrees of freedom, and the associated confidence intervals are based on a Student's $t$ value of 4.3. Inclusion of additional genomic loci in the reference gene panel could improve the confidence of the estimate of cfDNA load, 
and this may be necessary if more precise measurements are required (e.g. when measuring smaller fold changes).

We therefore recommend that, in the same way as reference messenger RNAs are selected on the basis of their stability for gene of interest normalisation [57, 58], a panel of genomic reference loci be screened in samples from the intended clinical cohort in order to ensure that a representative cross-section of the genome is measured in order to assign cfDNA load.

\section{Conclusions}

The potential of cfDNA as an analyte for tumour and prenatal diagnostics as well as a prognostic indicator for transplant rejection [59] and sepsis [60] is becoming increasingly apparent. A number of different techniques are being applied to circulating cfDNA analysis, from targeted approaches such as dPCR [61, 62] and deep sequencing of mutation hotspots [63], to whole exome and whole genome sequencing [64, 65]. Accurate quantification of total cfDNA will aid future clinical implementation of such approaches through quality assurance of technical performance (e.g. ensuring input quantity is sufficient to achieve the required sequencing depth). For noninvasive prenatal diagnosis of fetal aneuploidies, it is also important to characterise the fraction of total cfDNA which originates from the fetus [66].

In this study, we have investigated the efficiency of methods for extraction of cfDNA from plasma and have demonstrated how a spike-in containing fragment sizes relevant to cfDNA can be used to assess recovery of differently sized DNA. We have applied a strategy developed for standardisation of messenger RNA to cfDNA load measurements using multiple reference genes to minimise biases due to assay or genome location. This report is timely in raising awareness of the need, and establishing a benchmark, for standardisation of the extraction and quantification of cfDNA in these exciting fields of molecular diagnostics.

Acknowledgments The work described in this manuscript was funded by the UK National Measurement System. The authors thank Bio-Rad for provision of the QX100 Droplet Digital PCR system used for the dPCR experiments performed in this study.

Open Access This article is distributed under the terms of the Creative Commons Attribution License which permits any use, distribution, and reproduction in any medium, provided the original author(s) and the source are credited.

\section{References}

1. Hahn S, Jackson LG, Kolla V, Mahyuddin AP, Choolani M (2009) Noninvasive prenatal diagnosis of fetal aneuploidies and Mendelian disorders: new innovative strategies. Expert Rev Mol Diagn 9(6): 613-621
2. Stroun M, Anker P, Lyautey J, Lederrey C, Maurice PA (1987) Isolation and characterization of DNA from the plasma of cancer patients. Eur J Cancer Clin Oncol 23(6):707-712

3. Leon SA, Shapiro B, Sklaroff DM, Yaros MJ (1977) Free DNA in the serum of cancer patients and the effect of therapy. Cancer Res 37(3): 646-650

4. Lui YY, Woo KS, Wang AY, Yeung CK, Li PK, Chau E, Ruygrok P, Lo YM (2003) Origin of plasma cell-free DNA after solid organ transplantation. Clin Chem 49(3):495-496

5. Aung KL, Board RE, Ellison G, Donald E, Ward T, Clack G, Ranson M, Hughes A, Newman W, Dive C (2010) Current status and future potential of somatic mutation testing from circulating free DNA in patients with solid tumours. HUGO J 4(1-4):11-21

6. Crowley E, Di Nicolantonio F, Loupakis F, Bardelli A (2013) Liquid biopsy: monitoring cancer-genetics in the blood. Nat Rev Clin Oncol 10(8):472-484

7. Alfirevic Z, Sundberg K, Brigham S (2003) Amniocentesis and chorionic villus sampling for prenatal diagnosis. Cochrane Database Syst Rev 3, CD003252

8. Snyder TM, Khush KK, Valantine HA, Quake SR (2011) Universal noninvasive detection of solid organ transplant rejection. Proc Natl Acad Sci U S A 108(15):6229-6234

9. Kimura T, Holland WS, Kawaguchi T, Williamson SK, Chansky K, Crowley JJ, Doroshow JH, Lenz HJ, Gandara DR, Gumerlock PH (2004) Mutant DNA in plasma of lung cancer patients: potential for monitoring response to therapy. Ann N Y Acad Sci 1022:55-60

10. Page K, Hava N, Ward B, Brown J, Guttery DS, Ruangpratheep C, Blighe K, Sharma A, Walker RA, Coombes RC, Shaw JA (2011) Detection of HER2 amplification in circulating free DNA in patients with breast cancer. Br J Cancer 104(8):1342-1348

11. Benn P, Cuckle H, Pergament E (2013) Non-invasive prenatal testing for aneuploidy: current status and future prospects. Ultrasound Obstet Gynecol 42(1):15-33

12. Fleischhacker M, Schmidt B (2007) Circulating nucleic acids (CNAs) and cancer-a survey. Biochim Biophys Acta 1775(1): 181-232

13. Pinzani P, Salvianti F, Pazzagli M, Orlando C (2010) Circulating nucleic acids in cancer and pregnancy. Methods 50(4):302-307

14. Marzese DM, Hirose H, Hoon DS (2013) Diagnostic and prognostic value of circulating tumor-related DNA in cancer patients. Expert Rev Mol Diagn 13(8):827-844

15. Barrett AN, Zimmermann BG, Wang D, Holloway A, Chitty LS (2011) Implementing prenatal diagnosis based on cell-free fetal DNA: accurate identification of factors affecting fetal DNA yield. PLoS One 6(10):e25202

16. Wong D, Moturi S, Angkachatchai V, Mueller R, DeSantis G, van den Boom D, Ehrich M (2013) Optimizing blood collection, transport and storage conditions for cell free DNA increases access to prenatal testing. Clin Biochem 46(12):1099-1104

17. Hidestrand M, Stokowski R, Song K, Oliphant A, Deavers J, Goetsch M, Simpson P, Kuhlman R, Ames M, Mitchell M, Tomita-Mitchell A (2012) Influence of temperature during transportation on cell-free DNA analysis. Fetal Diagn Ther 31(2):122-128

18. Fleischhacker M, Schmidt B, Weickmann S, Fersching DM, Leszinski GS, Siegele B, Stotzer OJ, Nagel D, Holdenrieder S (2011) Methods for isolation of cell-free plasma DNA strongly affect DNA yield. Clin Chim Acta 412(23-24):2085-2088

19. Repiska G, Sedlackova T, Szemes T, Celec P, Minarik G (2013) Selection of the optimal manual method of cell free fetal DNA isolation from maternal plasma. Clin Chem Lab Med 51(6):11851189

20. Fong SL, Zhang JT, Lim CK, Eu KW, Liu Y (2009) Comparison of 7 methods for extracting cell-free DNA from serum samples of colorectal cancer patients. Clin Chem 55(3):587-589

21. Legler TJ, Liu Z, Mavrou A, Finning K, Hromadnikova I, Galbiati S, Meaney C, Hulten MA, Crea F, Olsson ML, Maddocks DG, Huang 
D, Fisher SA, Sprenger-Haussels M, Soussan AA, van der Schoot CE (2007) Workshop report on the extraction of foetal DNA from maternal plasma. Prenat Diagn 27(9):824-829

22. Huang DJ, Mergenthaler-Gatfield S, Hahn S, Holzgreve W, Zhong XY (2008) Isolation of cell-free DNA from maternal plasma using manual and automated systems. Methods Mol Biol 444:203-208

23. Page K, Guttery DS, Zahra N, Primrose L, Elshaw SR, Pringle JH, Blighe K, Marchese SD, Hills A, Woodley L, Stebbing J, Coombes RC, Shaw JA (2013) Influence of plasma processing on recovery and analysis of circulating nucleic acids. PLoS One 8(10):e77963

24. Holmberg RC, Gindlesperger A, Stokes T, Lopez D, Hyman L, Freed M, Belgrader P, Harvey J, Li Z (2013) Akonni TruTip ${ }^{\mathbb{B}}$ and Qiagen ${ }^{\circledR}$ methods for extraction of fetal circulating DNA - evaluation by realtime and digital PCR. PLoS One 8(8):e73068

25. Clausen FB, Krog GR, Rieneck K, Dziegiel MH (2007) Improvement in fetal DNA extraction from maternal plasma. Evaluation of the NucliSens magnetic extraction system and the QIAamp DSP virus kit in comparison with the QIAamp DNA blood mini kit. Prenat Diagn 27(1):6-10

26. Xue X, Teare MD, Holen I, Zhu YM, Woll PJ (2009) Optimizing the yield and utility of circulating cell-free DNA from plasma and serum. Clin Chim Acta 404(2):100-104

27. Pinzani P, Salvianti F, Cascella R, Massi D, De Giorgi V, Pazzagli M, Orlando C (2010) Allele specific Taqman-based real-time PCR assay to quantify circulating BRAFV600E mutated DNA in plasma of melanoma patients. Clin Chim Acta 411(17-18):1319-1324

28. Schmidt B, Weickmann S, Witt C, Fleischhacker M (2005) Improved method for isolating cell-free DNA. Clin Chem 51(8):1561-1563

29. Wang BG, Huang HY, Chen YC, Bristow RE, Kassauei K, Cheng CC, Roden R, Sokoll LJ, Chan DW, Shih IM (2003) Increased plasma DNA integrity in cancer patients. Cancer Res 63(14):3966-3968

30. Giacona MB, Ruben GC, Iczkowski KA, Roos TB, Porter DM, Sorenson GD (1998) Cell-free DNA in human blood plasma: length measurements in patients with pancreatic cancer and healthy controls. Pancreas 17(1):89-97

31. Jorgez CJ, Bischoff FZ (2009) Improving enrichment of circulating fetal DNA for genetic testing: size fractionation followed by whole gene amplification. Fetal Diagn Ther 25(3):314-319

32. Lo YM, Lun FM, Chan KC, Tsui NB, Chong KC, Lau TK, Leung TY, Zee BC, Cantor CR, Chiu RW (2007) Digital PCR for the molecular detection of fetal chromosomal aneuploidy. Proc Natl Acad Sci U S A 104(32):13116-13121

33. Barrett AN, McDonnell TCR, Chan KCA, Chitty LS (2012) Digital PCR analysis of maternal plasma for noninvasive detection of sickle cell anemia. Clin Chem 58(6):1026-1032

34. Gormally E, Caboux E, Vineis P, Hainaut P (2007) Circulating free DNA in plasma or serum as biomarker of carcinogenesis: practical aspects and biological significance. Mutat Res 635(2-3):105-117

35. Bustin SA, Nolan T (2004) Pitfalls of quantitative real-time reversetranscription polymerase chain reaction. J Biomol Tech 15(3):155166

36. Sanders R, Huggett JF, Bushell CA, Cowen S, Scott DJ, Foy CA (2011) Evaluation of digital PCR for absolute DNA quantification. Anal Chem 83(17):6474-6484

37. Board RE, Williams VS, Knight L, Shaw J, Greystoke A, Ranson M, Dive C, Blackhall FH, Hughes A (2008) Isolation and extraction of circulating tumor DNA from patients with small cell lung cancer. Ann N Y Acad Sci 1137:98-107
38. Cannas A, Kalunga G, Green C, Calvo L, Katemangwe P, Reither K, Perkins MD, Maboko L, Hoelscher M, Talbot EA, Mwaba P, Zumla AI, Girardi E, Huggett JF, T.B. trDNA consortium (2009) Implications of storing urinary DNA from different populations for molecular analyses. PLoS One 4(9):e6985

39. Birch L, English CA, O'Donoghue K, Barigye O, Fisk NM, Keer JT (2005) Accurate and robust quantification of circulating fetal and total DNA in maternal plasma from 5 to 41 weeks of gestation. Clin Chem 51(2):312-320

40. Gotoh T, Hosoi H, Iehara T, Kuwahara Y, Osone S, Tsuchiya K, Ohira M, Nakagawara A, Kuroda H, Sugimoto T (2005) Prediction of MYCN amplification in neuroblastoma using serum DNA and real-time quantitative polymerase chain reaction. J Clin Oncol 23(22):5205-5210

41. Hasler J, Strub K (2006) Alu elements as regulators of gene expression. Nucleic Acids Res 34(19):5491-5497

42. Schmid CW, Deininger PL (1975) Sequence organization of the human genome. Cell 6(3):345-358

43. Huggett JF, Foy CA, Benes V, Emslie K, Garson JA, Haynes R, Hellemans J, Kubista M, Mueller RD, Nolan T, Pfaffl MW, Shipley GL, Vandesompele J, Wittwer CT, Bustin SA (2013) The digital MIQE guidelines: minimum information for publication of quantitative digital PCR experiments. Clin Chem 59(6):892-902

44. Hindson BJ, Ness KD, Masquelier DA, Belgrader P, Heredia NJ, Makarewicz AJ, Bright IJ, Lucero MY, Hiddessen AL, Legler TC, Kitano TK, Hodel MR, Petersen JF, Wyatt PW, Steenblock ER, Shah PH, Bousse LJ, Troup CB, Mellen JC, Wittmann DK, Erndt NG, Cauley TH, Koehler RT, So AP, Dube S, Rose KA, Montesclaros L, Wang S, Stumbo DP, Hodges SP, Romine S, Milanovich FP, White HE, Regan JF, Karlin-Neumann GA, Hindson CM, Saxonov S, Colston BW (2011) High-throughput droplet digital PCR system for absolute quantitation of DNA copy number. Anal Chem 83(22): 8604-8610

45. Whale AS, Huggett JF, Cowen S, Speirs V, Shaw J, Ellison S, Foy CA, Scott DJ (2012) Comparison of microfluidic digital PCR and conventional quantitative PCR for measuring copy number variation. Nucleic Acids Res 40(11):e82

46. Vandesompele J, De Preter K, Pattyn F, Poppe B, Van Roy N, De Paepe A, Speleman F (2002) Accurate normalization of real-time quantitative RT-PCR data by geometric averaging of multiple internal control genes. Genome Biol 3(7):research0034.1

47. R Core Team (2013) R: a language and environment for statistical computing. R Foundation for Statistical Computing, Vienna

48. Hayden RT, Gu Z, Ingersoll J, Abdul-Ali D, Shi L, Pounds S, Caliendo AM (2013) Comparison of droplet digital PCR to realtime PCR for quantitative detection of cytomegalovirus. J Clin Microbiol 51(2):540-546

49. Al-Soud WA, Rådström P (2001) Purification and characterization of PCR-inhibitory components in blood cells. J Clin Microbiol 39(2): 485-493

50. Tsang JC, Lo YM (2007) Circulating nucleic acids in plasma/serum. Pathology 39(2):197-207

51. Huggett J, Novak T, Garson J, Green C, Morris-Jones S, Miller R, Zumla A (2008) Differential susceptibility of PCR reactions to inhibitors: an important and unrecognised phenomenon. BMC Res Notes 1(1):70

52. Chiu RW, Poon LL, Lau TK, Leung TN, Wong EM, Lo YM (2001) Effects of blood-processing protocols on fetal and total DNA quantification in maternal plasma. Clin Chem 47(9): $1607-1613$ 
53. Moyzis RK, Buckingham JM, Cram LS, Dani M, Deaven LL, Jones MD, Meyne J, Ratliff RL, Wu JR (1988) A highly conserved repetitive DNA sequence, (TTAGGG)n, present at the telomeres of human chromosomes. Proc Natl Acad Sci U S A 85(18):6622-6626

54. Kitzman JO, Snyder MW, Ventura M, Lewis AP, Qiu R, Simmons LE, Gammill HS, Rubens CE, Santillan DA, Murray JC, Tabor HK, Bamshad MJ, Eichler EE, Shendure J (2012) Noninvasive wholegenome sequencing of a human fetus. Sci Transl Med 4(137): $137 \mathrm{ra176}$

55. Fan HC, Gu W, Wang J, Blumenfeld YJ, El-Sayed YY, Quake SR (2012) Non-invasive prenatal measurement of the fetal genome. Nature 487(7407):320-324

56. Bustin SA, Benes V, Garson JA, Hellemans J, Huggett J, Kubista M, Mueller R, Nolan T, Pfaffl MW, Shipley GL, Vandesompele J, Wittwer CT (2009) The MIQE guidelines: minimum information for publication of quantitative real-time PCR experiments. Clin Chem 55(4):611-622

57. Fox BC, Devonshire AS, Schutte ME, Foy CA, Minguez J, Przyborski S, Maltman D, Bokhari M, Marshall D (2010) Validation of reference gene stability for APAP hepatotoxicity studies in different in vitro systems and identification of novel potential toxicity biomarkers. Toxicol In Vitro 24(7):1962-1970

58. Huggett J, Dheda K, Bustin S, Zumla A (2005) Real-time RT-PCR normalisation; strategies and considerations. Genes Immun 6(4): 279-284

59. Beck J, Bierau S, Balzer S, Andag R, Kanzow P, Schmitz J, Gaedcke J, Moerer O, Slotta JE, Walson P, Kollmar O, Oellerich M, Schutz E (2013) Digital Droplet PCR for rapid quantification of donor DNA in the circulation of transplant recipients as a potential universal biomarker of graft injury. Clin Chem 59(12):1732-1741

60. Dwivedi D, Toltl L, Swystun L, Pogue J, Liaw K-L, Weitz J, Cook D, Fox-Robichaud A, Liaw P, Group tCCCTB (2012) Prognostic utility and characterization of cell-free DNA in patients with severe sepsis. Crit Care 16(4):R151

61. Taly V, Pekin D, Benhaim L, Kotsopoulos SK, Le Corre D, Li $\mathrm{X}$, Atochin I, Link DR, Griffiths AD, Pallier K, Blons $\mathrm{H}$, Bouche O, Landi B, Hutchison JB, Laurent-Puig P (2013) Multiplex picodroplet digital PCR to detect KRAS mutations in circulating DNA from the plasma of colorectal cancer patients. Clin Chem 59(12):1722-1731

62. Gevensleben H, Garcia-Murillas I, Graeser MK, Schiavon G, Osin P, Parton M, Smith IE, Ashworth A, Turner NC (2013) Noninvasive detection of HER2 amplification with plasma DNA digital PCR. Clin Cancer Res 19(12):3276-3284

63. Forshew T, Murtaza M, Parkinson C, Gale D, Tsui DW, Kaper F, Dawson SJ, Piskorz AM, Jimenez-Linan M, Bentley D, Hadfield J, May AP, Caldas C, Brenton JD, Rosenfeld N (2012) Noninvasive identification and monitoring of cancer mutations by targeted deep sequencing of plasma DNA. Sci Trans1 Med 4(136):136ra168

64. Murtaza M, Dawson SJ, Tsui DW, Gale D, Forshew T, Piskorz AM, Parkinson C, Chin SF, Kingsbury Z, Wong AS, Marass F, Humphray S, Hadfield J, Bentley D, Chin TM, Brenton JD, Caldas C, Rosenfeld N (2013) Non-invasive analysis of acquired resistance to cancer therapy by sequencing of plasma DNA. Nature 497(7447):108-112

65. Lo YM (2013) Non-invasive prenatal testing using massively parallel sequencing of maternal plasma DNA: from molecular karyotyping to fetal whole-genome sequencing. Reprod Biomed Online 27(6):593598
66. Buysse K, Beulen L, Gomes I, Gilissen C, Keesmaat C, Janssen IM, Derks-Willemen JJ, de Ligt J, Feenstra I, Bekker MN, van Vugt JM, Geurts van Kessel A, Vissers LE, Faas BH (2013) Reliable noninvasive prenatal testing by massively parallel sequencing of circulating cell-free DNA from maternal plasma processed up to $24 \mathrm{~h}$ after venipuncture. Clin Biochem 46(18):1783-1786

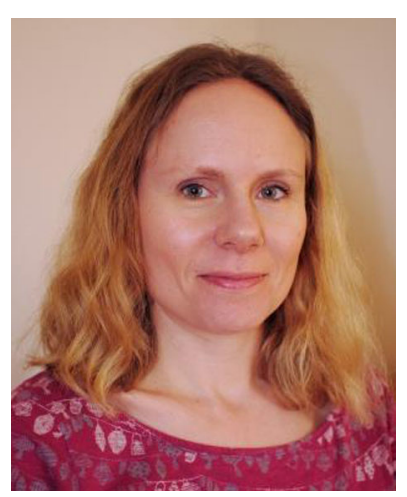

Alison Devonshire is a senior researcher at LGC Ltd, UK, specialising in nucleic acid measurements and their application in clinical diagnostics and cell-based assays. Her current research interests include single-cell analysis, standardisation of molecular methods for infectious diseases and messenger RNA biomarkers.

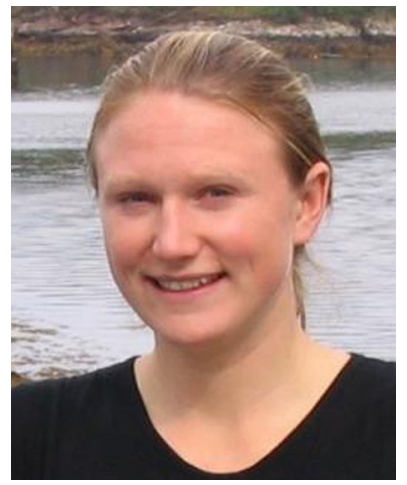

Alexandra Whale is a researcher in the Molecular and Cell Biology Team at LGC Ltd, UK, with a focus on nucleic acid metrology. Her areas of expertise are trace detection of nucleic acids from complex sources, such as cellfree DNA from blood plasma, using digital PCR technologies. Recent research has also included the use of digital PCR for investigation of measurement bias in low copy number samples.

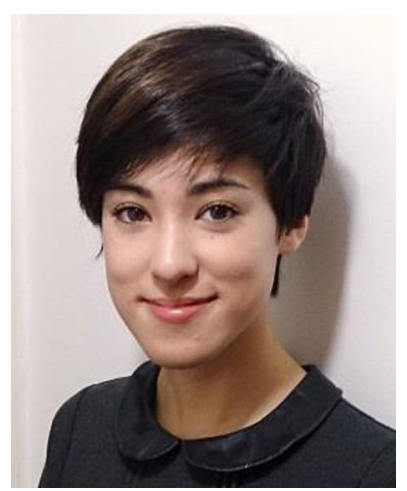

Alice Gutteridge is a research analyst in the Molecular and Cell Biology Team at LGC Ltd, UK. She currently works on a variety of projects pertaining to the validation and standardisation of methods that detect and quantify nucleic acid targets. 


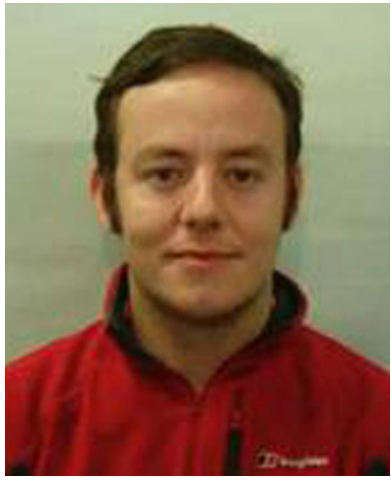

Gerwyn Jones is a researcher in the Molecular and Cell Biology Team at LGC Ltd, UK. He has over 10 years' experience in genomics research, including 8 years as a commercial R\&D scientist, with a particular focus on PCR and quantitative PCR reagent development. His current research interests include nucleic acid metrology, molecular diagnostics and next-generation sequencing.

Simon Cowen joined LGC Ltd, UK, as a physicist, but retrained in bioinformatics and now leads the company's Statistics Team. $\mathrm{He}$ is involved in a wide range of measurement research activity, but is particularly interested in the analysis of digital PCR and quantitative PCR data, as well as the statistical interpretation of forensic DNA evidence.

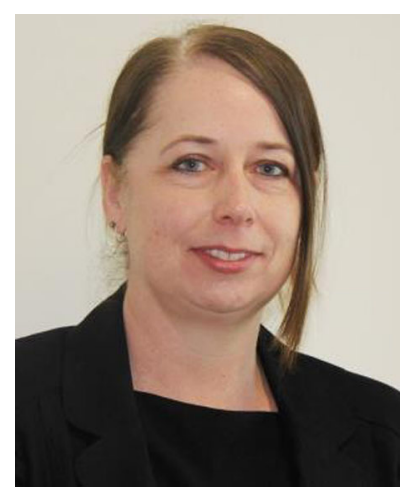

Carole Foy is the principal scientist for molecular biology at LGC Ltd, UK, providing scientific strategy and lead on nucleic acid measurement. Her projects focus on improving the overall quality of nucleic acid measurements and measurement platforms and include developing approaches to minimise the impact of sources of variability on genomic measurements and improving confidence through the development of appropriate standards, quality metrics, evaluation protocols and best practice guidelines.

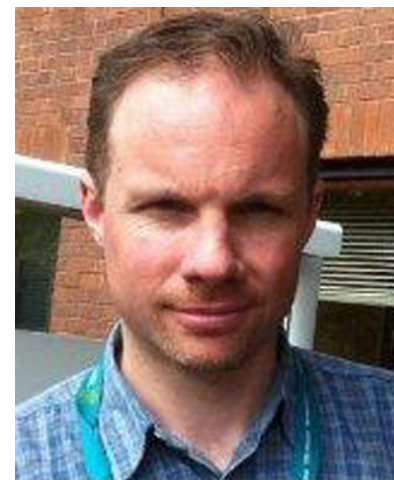

Jim Huggett trained as a geneticist and worked as a senior research fellow at University College London studying infectious disease diagnosis. For the past 4 years he has led the nucleic acid metrology research in LGC's Molecular and Cell Biology Team, where he investigates the measurement challenges associated with established and novel technologies for molecular measurement and diagnostics. 